\title{
Stress Characteristics and Overload Failure Analysis of Cemented Sand and Gravel Dam in Naheng Reservoir
}

https://doi.org/10.1515/phys-2019-0100

Received Jul 26, 2019; accepted Sep 09, 2019

\begin{abstract}
On the basis of the Naheng Reservoir Project, the stress, strain, and deformation of Naheng Reservoir cemented sand and gravel dam are simulated numerical simulation and structural model test. The stress and deformation laws of the dam under the combined load of dead weight and normal water level are analyzed using the structural model test method. Compared with the finite element numerical simulation, the results reflect the stress and deformation distribution law of the dam. Then, the failure mode of the cemented sand and gravel dam can be visualized by using the water load overload method to conduct the structural model failure test, and the failure mode and failure mechanism of the cemented sand and gravel dam can be discussed. The research results lay a foundation for further determining the safety degree analysis of cemented sand and gravel dam.
\end{abstract}

Keywords: cemented sand and gravel dam; stress characteristics; overload failure analysis; numerical simulation; structural model test

PACS: 92.40.Xx, 81.70.-q, 46.70.-p, 02.60.-x

\section{Introduction}

In recent years, with the development of hydropower construction in China, the state has gradually shifted the focus of hydropower construction to the western region. The cemented sand and gravel(CSG) dam has many advantages [1-3], such as low stress level, large relative volume, dam body symmetry, dam structure stability, etc., which is

\footnotetext{
${ }^{\star}$ Corresponding Author: Xin Chen: College of Water Resources \& Hydropower, Sichuan University, Chengdu 610065, China; Email: 393871958@qq.com

Zhaoqiang Wang: College of Water Resources \& Hydropower, Sichuan University, Chengdu 610065, China
}

considered by international dam experts to be a dam with good seismic performance. Cemented sand and gravel (CSG) dam construction technology is similar to RCC dam construction technology, and the construction method is the same. As the maximum particle size of coarse aggregate can reach $250 \mathrm{~mm}$ or $300 \mathrm{~mm}$, its compaction thickness can generally reach $40 \sim 60 \mathrm{~cm}$, which can significantly accelerate the roller compaction speed [4]. However, the research on this type of dam in China has just started, and the existing research results in China cannot meet the requirements of practical applications such as design and construction. The theoretical for structural performance, material performance and failure mechanism of cemented sand and gravel dam is not enough, which restricts the development of this type of dam.

Therefore, on the basis of the Naheng Reservoir Project, the stress, strain and deformation of Naheng Reservoir cemented sand and gravel dam are simulated by using the method of numerical simulation [5-13] and model test [14-26]. The stress and deformation laws of the dam under the combined load of dead weight and normal water level are analyzed by using the structural stress model test method. Compared with the finite element numerical simulation, the results reflect the stress and deformation distribution law of the dam. Then, the failure mode of the cemented sand and gravel dam can be visualized by using the water load overload method to conduct the structural model failure test, and the failure mode and failure mechanism of the cemented sand and gravel dam can be discussed. The research results lay a foundation for further determining the safety degree analysis of cemented sand and gravel dam.

\section{Project Profile}

The Naheng Reservoir Project is located in the upper reaches of Naheng River, a first-grade tributary of the Naheng River in Funing County, Yunnan Province, near Nagheng Village. The total storage capacity of the reservoir

OOpen Access. (c) 2019 Z. Wang and X. Chen, published by De Gruyter. (Cc) BY 4.0 License 
is 12.48 million $\mathrm{m} 3$, the normal storage level of the reservoir is $963.80 \mathrm{~m}$, the corresponding downstream water level is $900.00 \mathrm{~m}$, the designed flood level is $965.06 \mathrm{~m}$, the corresponding downstream water level is $902.96 \mathrm{~m}$, the checked flood level is $966.04 \mathrm{~m}$, the corresponding downstream water level is $903.51 \mathrm{~m}$, and the dead water level is $928.16 \mathrm{~m}$. The design scheme of Naheng Reservoir cemented sand and gravel dam is as follows. The height of the dam crest is $967.00 \mathrm{~m}$, the height of the wave wall is $968.20 \mathrm{~m}$, the lowest height of the foundation is $892.50 \mathrm{~m}$, the highest height of the dam is $74.50 \mathrm{~m}$, and the axis length of the dam is $167.00 \mathrm{~m}$. It is divided into five sections, the longest section of the dam is $48.00 \mathrm{~m}$, the smallest section is $26.00 \mathrm{~m}$, and the width of the dam crest is $6.00 \mathrm{~m}$. The upstream slope of the dam body above the elevation of $956.00 \mathrm{~m}$ is a straight slope and the slope below is 1:0.6, while the downstream dam slope is 1:0.6 and the elevation of the starting point is 956.00m.

\section{Finite Element Modeling of Deformation and Stress Characteristics}

\subsection{Finite Element Model}

The three-dimensional finite element calculation range of Naheng Reservoir cemented sand and gravel dam is as follows: take $127 \mathrm{~m}$ upstream from dam heel (i.e. about 2 times the dam height from upstream boundary to dam heel) and $127 \mathrm{~m}$ downstream from dam toe (i.e. about 2 times the dam height from downstream boundary to dam toe). Take $127 \mathrm{~m}$ straight down from the foundation surface. In ANSYS modeling, the coordinate system is defined as:

$\mathrm{X}$ axis: along the river, from upstream to downstream;

Y axis: lead upward, from the bottom to the surface; $\mathrm{Z}$ axis: horizontal river direction, from left bank to right bank.

The boundary conditions are as follows. The bottom of the bedrock is subject to three-direction constraint; oneway constraint of $\mathrm{X}$ direction is applied to the two sides of the normal direction in the $\mathrm{X}$ direction, and one-way constraint of $Z$ direction is applied to the two sides of the normal direction in the $Z$ direction.The model adopts eightnode hexahedral elements, with a total of 77,490 nodes and 67,797 elements. The calculation model is shown in Figure 1.

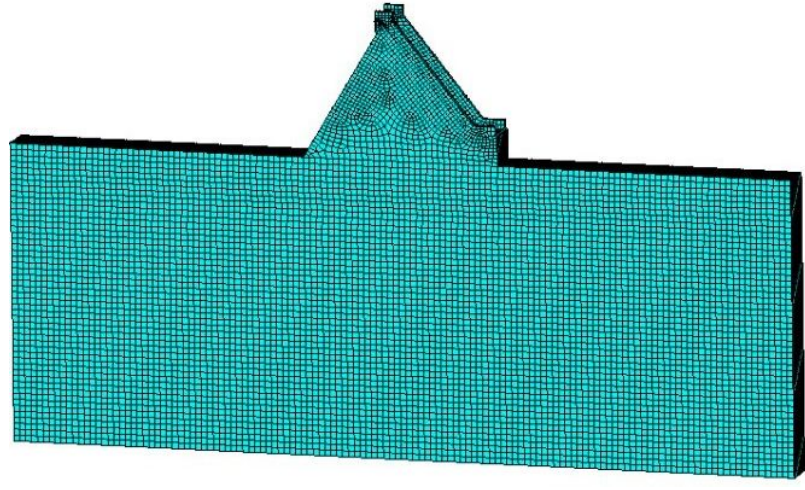

Figure 1: 3D finite element model of dam body

\subsection{Constitutive model}

Cemented sand and gravel materials have similar stressstrain curves with concrete materials, so ANSYS elastoplastic d-p model can be used as the constitutive model of cemented sand and gravel dam body and foundation materials for nonlinear numerical simulation. The $d-p$ yield criterion can be expressed as:

$$
\sigma_{e}=3 \beta \sigma_{m}+\sqrt{\frac{1}{2}\{S\}^{T}[M]\{S\}}=\sigma_{y}
$$

Where, $\sigma_{e}$ is the modified equivalent stress, $\beta$ is the material constant, $\sigma_{m}$ is the average stress, $\{\mathrm{S}\}$ is the deviant stress, and $[\mathrm{M}]$ is the constant matrix. The material constant $\beta$ and yield strength $\sigma_{y}$ can be calculated by equations (2) and (3) respectively:

$$
\begin{gathered}
\beta=\frac{2 \sin \varphi}{\sqrt{3}(3-\sin \varphi)} \\
\sigma_{y}=\frac{6 c \cos \varphi}{\sqrt{3}(3-\sin \varphi)}
\end{gathered}
$$

In addition, when the elastic-plastic $d-p$ model is used in ANSYS, the value of dilation angle $\phi_{f}$ should also be input. In this simulation calculation, the dilation angle is set to equal to the angle of internal friction, subject to the associated flow law, and the internal friction angle is expressed by the friction coefficient.Initial material simulation calculation parameters of dam body, foundation 1 and foundation 2 are shown in Table 1, with deep foundation as foundation 2 and shallow foundation as foundation 1 .

\section{Structural Model Test}

The stress distribution and structural characteristics of CSG dam foundation under normal operation condition 
Table 1: Mechanical parameters for each region

\begin{tabular}{cccccc}
\hline Position & $\begin{array}{c}\text { Elastic } \\
\text { modulus } / \mathrm{GPa}\end{array}$ & $\begin{array}{c}\text { Poisson } \\
\text { ratio }\end{array}$ & Density $/ \mathrm{kg} \cdot \mathrm{m}^{-3}$ & Cohesion $/ \mathrm{MPa}$ & Friction coefficient \\
\hline Dam boday & 11 & 0.21 & 2400 & 0.9 & 1 \\
Foundation 1 & 5 & 0.2 & 2500 & 0.8 & 0.9 \\
Foundation 2 & 5.5 & 0.21 & 2550 & 1.1 & 1.1 \\
\hline
\end{tabular}

are studied physical model test. In order to realize the research content, the structural stress model test method is adopted. As the structural model requires the measured deformation to be converted into stress through hooke's law, the linear elastic gypsum material is used to make the dam model according theory. The stress model test of dam structure is carried out to analyze the stress distribution of CSG dam body and foundation under normal operation, and the loading and measuring system of model state is tested to explore the rationality of model test design.

\subsection{Structural model test scheme}

The failure test of structural model is divided into elastic stage and plastic stage. According to the requirements of similarity theory, the model must meet the stress deformation and the strength characteristics similar to the prototype in both elastic-plastic stage. According to the elastic mechanics, the model should be similar to the prototype in terms of the physical equation, geometric equation and boundary conditions when the structure is in the elastic stage after being stressed. Similarly, the stress and strain of the model in the plastic stage still follow the boundary conditions, equilibrium equation, and geometric equations, so the similarity relationship derived from the geometric equations, equilibrium equation, and boundary conditions is still applicable in the plastic stage. However, since the relationship between stress and strain in the plastic stage no longer obeys law in the elastic stage, it is necessary to deduce the corresponding similarity relationship according to the physical equation in the plastic stage. In addition, the failure test also requires that the strength characteristics of the model should be similar to the prototype. The model size determined by the above similarity relation can truly reflect the stress characteristics and overload failure.

In this test, a typical section of CSG dam was selected for simulation. Figure 2 a typical section of non-spillway dam section, the dam height is $59.3 \mathrm{~m}$ and the upstream downstream slope ratio is 1:0.6. The test loads are dead weight, static pressure, and uplift pressure. It is assumed

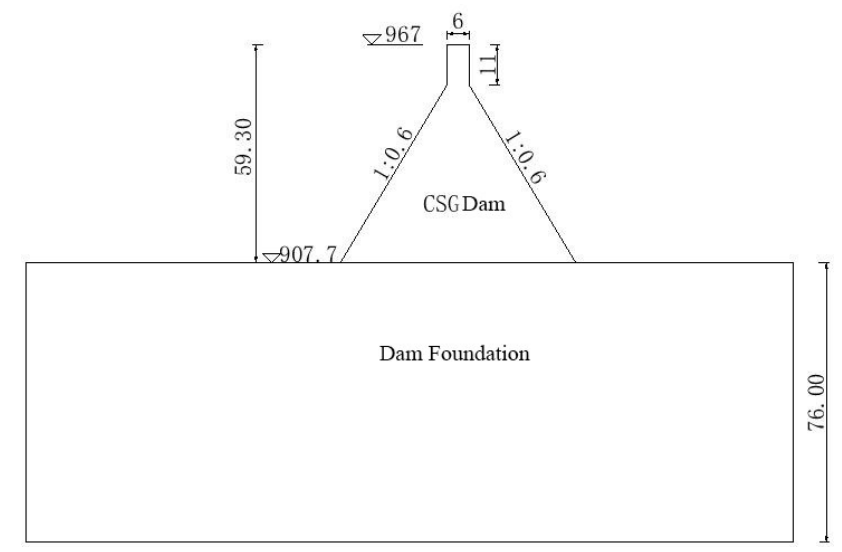

Figure 2: Size drawing of CSG dam prototype (unit :m)

Table 2: Dam prototype material parameters

\begin{tabular}{cccc}
\hline Material & $\begin{array}{c}\text { Density / } \\
\left(\mathrm{kg} / \mathrm{m}^{3}\right)\end{array}$ & $\begin{array}{c}\text { Elasticity } \\
\text { modulus / } \\
\mathrm{GPa}\end{array}$ & $\begin{array}{c}\text { Poisson } \\
\text { ratio }\end{array}$ \\
\hline Dam body & 2360 & 11 & 0.2 \\
Dam foundation & 2650 & 5.5 & 0.2 \\
\hline
\end{tabular}

that the uplift pressure is reduced to of the water head at the drainage hole curtain of dam heel, and the uplift pressure is distributed linearly at the bottom of dam. Due to the limitation of uplift pressure simulation in structural model, is simulated by reducing the dead weight of dam body.

By referring to the material mechanics parameters of the dam body like CSG dam and the engineering geological data of the bedrock rock mass in the Naheng reservoir dam, and considering the loading capacity of the actual test and the material properties, the dam and foundation material mechanics are determined comprehensively in the following Table 2.

The objects of this test are the typical non-overflow dam section and foundation of CSG dam, and the width of the dam section and foundation is $28 \mathrm{~m}$. In order to meet the requirements of structural model test, the dam body gypsum density is $0.801 \mathrm{~g} / \mathrm{cm}^{3}$, the elastic modulus is $348.34 \mathrm{MPa}$, the dam foundation gypsum density is 
Table 3: Material parameter table of test model

\begin{tabular}{cccc}
\hline Material & $\begin{array}{c}\text { Density / } \\
\left(\mathrm{kg} / \mathrm{m}^{3}\right)\end{array}$ & $\begin{array}{c}\text { Elasticity } \\
\text { modulus } \\
/ \mathrm{GPa}\end{array}$ & $\begin{array}{c}\text { Poisson } \\
\text { ratio }\end{array}$ \\
\hline Dam body & 801 & 0.34 & 0.2 \\
Dam foundation & 585 & 0.17 & 0.2 \\
\hline
\end{tabular}
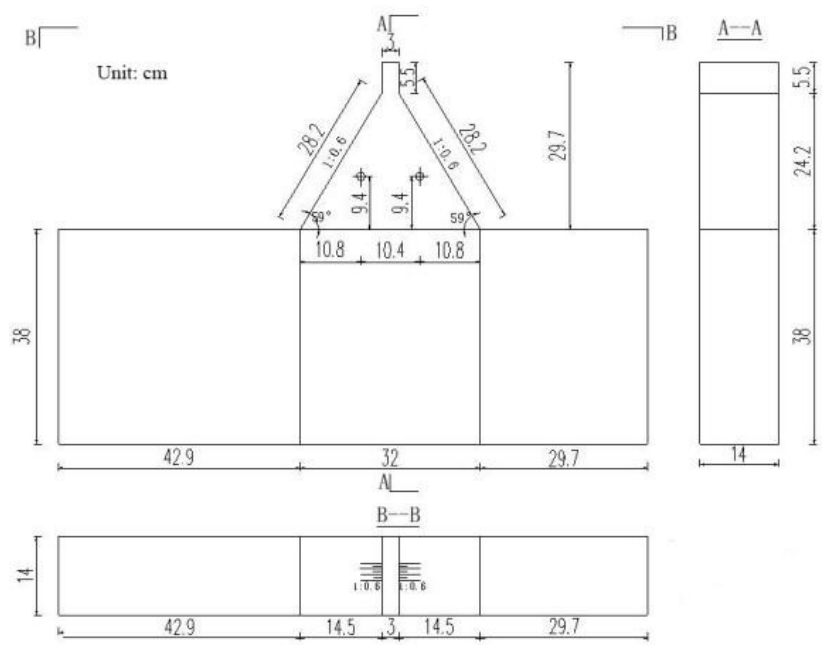

Figure 3: Dam model size and dam foundation range

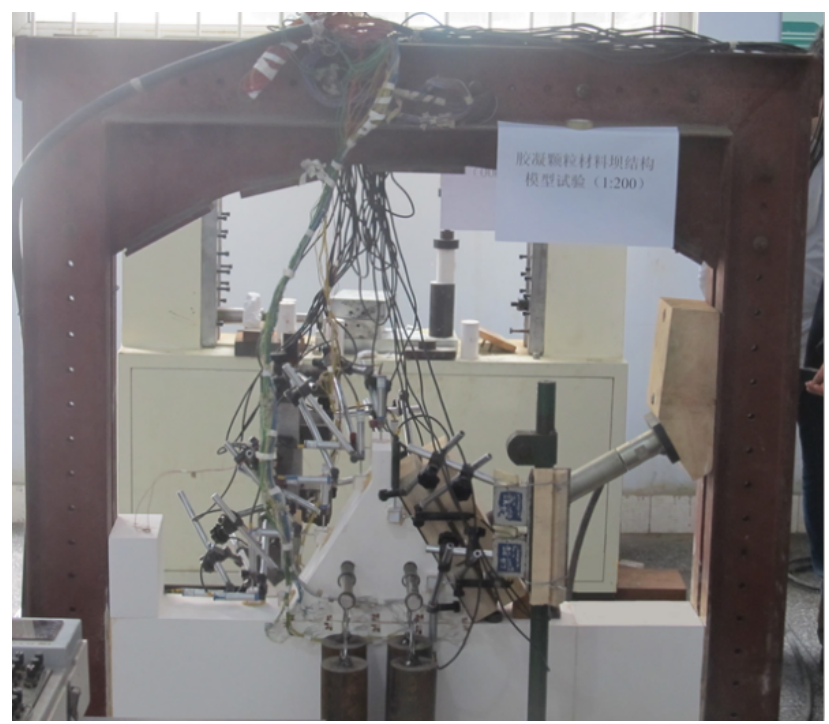

Figure 4: Actual dam model

$0.585 \mathrm{~g} / \mathrm{cm}^{3}$, and the elastic modulus is $170.07 \mathrm{MPa}$. The model dam is made of dry gypsum material. According to the experimental theory, the simulated range of this test is: the length of the upstream side of the dam foundation is 1.4 times the height, and the length of the downstream side of the foundation is 1.0 times the dam height and the depth

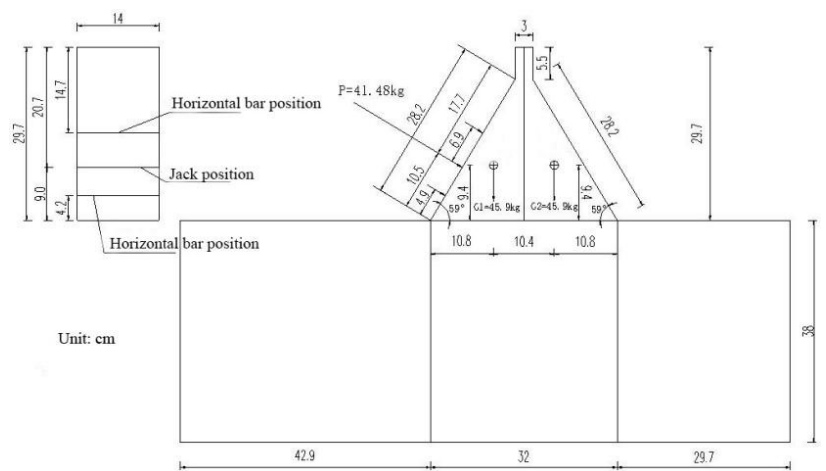

Figure 5: Load calculation and loading diagram

below the foundation is 1.28 times the dam height. According to the prototype material parameters table, the model material parameters are obtained through similarity scale conversion, as shown in Table 3.

The dam and foundation size determined according to the geometric scale are shown in Figure 3, and the actual dam model is shown in Figure 4.

\subsection{Simulated load and loading system}

The main loads simulated by the test are the dead weight of the dam and the water pressure on the upstream dam surface. First, load of the prototype is calculated, and vertical load applied on the model and the water load on the upstream dam surface the similarity principle. Gypsum is lighter and cannot meet bulk density similarity. Gravity load similarity is realized by applying external force. In the test, a lifting block is adopted at the center of gravity of the dam body. The water load on the upstream dam surface is applied by the jack in the test, and the load is transmitted to the dam surface by the pressure plate in two times.

Load simulation and loading system layout drawings 5 and 6 are shown. In the process of water loading on the upstream dam surface, two horizontal bars are used to distribute the concentrated load of the jack. The force of a jack is distributed to two operating points. The upper load is of the total load, and the lower iron bar bears of the load. In order to make the concentrated force act on the model uniformly, the transmission pressure plate is set to coincide with the dam face. At the same time, the contact surface between the pressure plate and the dam body is laid with plastic sheets to reduce the mutual friction restraint. 


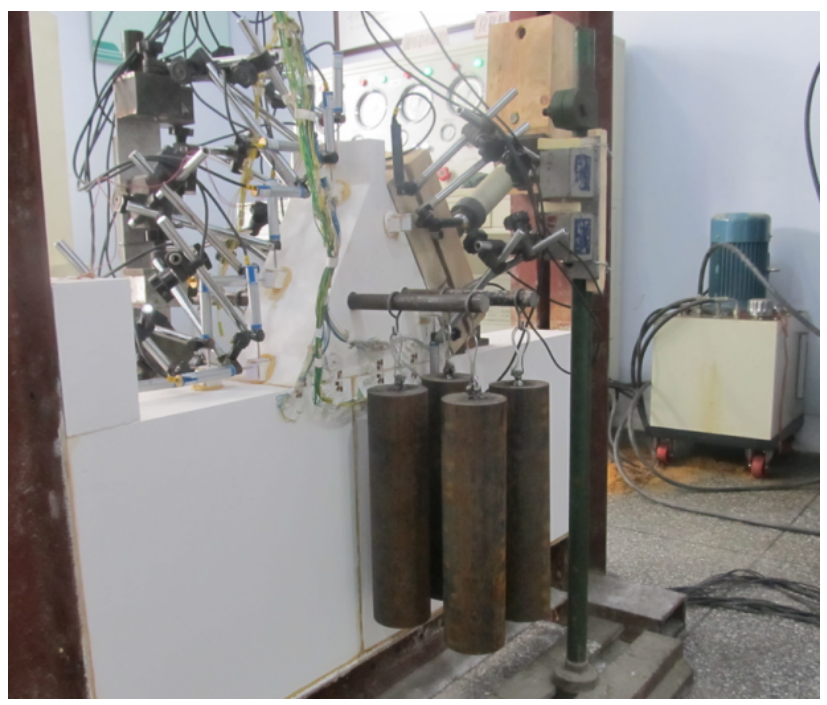

Figure 6: Model loading mode and measurement system layout

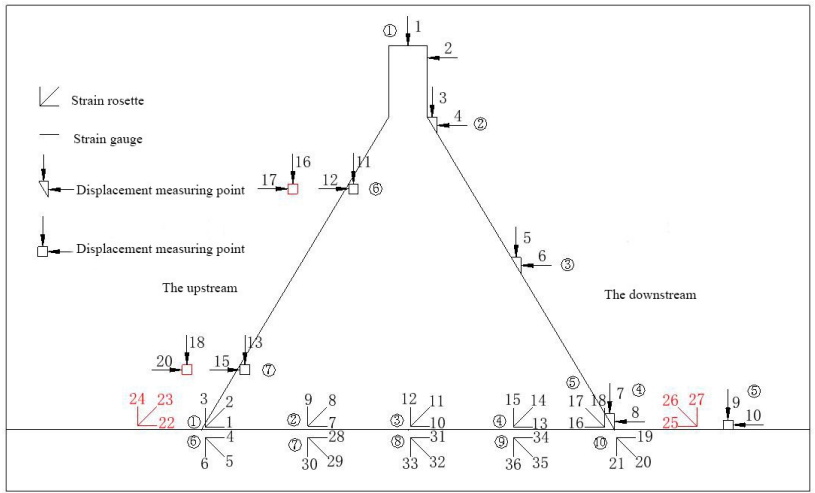

Figure 7: Arrangement of strain and displacement measurement points of the model

\subsection{Model measurement system}

The measuring system of the model is divided into strain measuring and displacement measuring system of dam body and dam respectively. The strain is monitored by resistance strain gauge. At the same time, a compensation plate is set to eliminate the temperature effect.Numerical testing device UCAM-70A to measure data. Five strain measuring points are arranged on the dam foundation. At the same time, two strain measuring points are arranged on the dam heel and toe respectively, and a row of measuring points are also arranged on the dam foundation near the foundation plane. SP-10A displacement digital indicator was used to measure the surface displacement of the dam body. Horizontal and vertical displacement sensors are arranged at dam height respectively on the left and right sides of the upstream face of the dam. Horizontal and vertical displacement sensors are arranged at the top of downstream dam, the turning point of downstream dam and $1 / 2 \mathrm{dam}$. The measurement arrangement is shown in Figure 7.

\subsection{The test process}

Before the formal test, the model is preloaded repeatedly to eliminate the gap between additional deformation and various parts of the model, and then the incremental pressure method is applied step by step. In this experiment, a steel rod is used to simulate the dead weight. 8 10 minutes after loading and unloading of each level of load, so that the stress and strain distribution of the dam body is uniform.

\section{Comparison and Analysis between the Experimental Results and the Finite Element Numerical Simulation}

\subsection{Comparison and analysis of stress deformation results of dam body under dead weight and normal water level}

According to the test, the strain and displacement of the corresponding measuring point are obtained. Hooke's law is used to convert the collected strain data into the stress in the dam, and then the model stress and displacement are converted into the stress and displacement of the prototype dam according to the similar relationship. The stress and displacement distribution of the dam body under dead weight and normal water level are shown in Figure 8 and Figure 9. Figure 10 and 11 are the stress vector diagram and displacement diagram of the corresponding measuring point of the cemented sand and gravel dam body obtained by finite element calculation under the same condition. In the stress diagram, the tensile stress is positive and the compressive stress is negative. In horizontal displacement, a positive value represents a downstream shift. In horizontal displacement, a positive value represents a downstream shift. Table 4 and Table 5 respectively show the comparison of point stress and displacement calculation results of corresponding test and finite element.

As can be seen from Figure 8 , the dam body and foundation are all under pressure on the whole, and only a tensile stress appears at the heel. From heel to toe, the com- 
Table 4: Comparison of test and finite element stress calculation results

\begin{tabular}{|c|c|c|c|c|c|c|c|c|c|c|c|}
\hline \multirow[t]{2}{*}{ Calculation } & \multirow{2}{*}{$\begin{array}{c}\text { Principal } \\
\text { stress/MPa }\end{array}$} & \multicolumn{10}{|c|}{ Measurement point number } \\
\hline & & (1) & (2) & (3) & (4) & (5) & (6) & (7) & 8 & (9) & 10 \\
\hline \multirow[t]{2}{*}{ Experiment } & $\sigma 1$ & -0.18 & -0.37 & -0.68 & -0.67 & -1.42 & -0.17 & -0.34 & -0.45 & -0.63 & -1.32 \\
\hline & $\sigma 3$ & 0.35 & -0.11 & -0.09 & -0.15 & -0.22 & -0.12 & -0.10 & -0.05 & -0.13 & -0.19 \\
\hline \multirow{2}{*}{$\begin{array}{c}\text { Finite } \\
\text { element }\end{array}$} & $\sigma 1$ & -0.63 & -0.73 & -0.79 & -0.97 & -1.71 & -0.64 & -0.81 & -0.86 & -0.94 & -1.29 \\
\hline & $\sigma 3$ & -0.18 & -0.19 & -0.20 & -0.24 & -0.13 & 0.07 & -0.11 & -0.13 & -0.16 & -0.24 \\
\hline
\end{tabular}

Table 5: Comparison of test and finite element displacement calculation results

\begin{tabular}{ccccc}
\hline $\begin{array}{c}\text { Number of } \\
\text { measuring } \\
\text { points }\end{array}$ & \multicolumn{2}{c}{ Experiment } & \multicolumn{2}{c}{ Finite element } \\
Vertical & Level & Vertical & Level \\
\hline (1) & -0.7 & 0.2 & -1.40 & 0.347 \\
$(2)$ & -0.6 & 0.2 & -1.39 & 0.316 \\
(3) & -0.5 & 0.1 & -1.25 & 0.265 \\
(4) & -0.4 & 0.1 & -0.93 & 0.166 \\
(5) & -0.6 & -0.1 & -0.53 & -0.012 \\
(6) & -0.5 & 0.25 & -1.36 & 0.308 \\
(7) & -0.4 & 0.3 & -1.26 & 0.327 \\
\hline
\end{tabular}

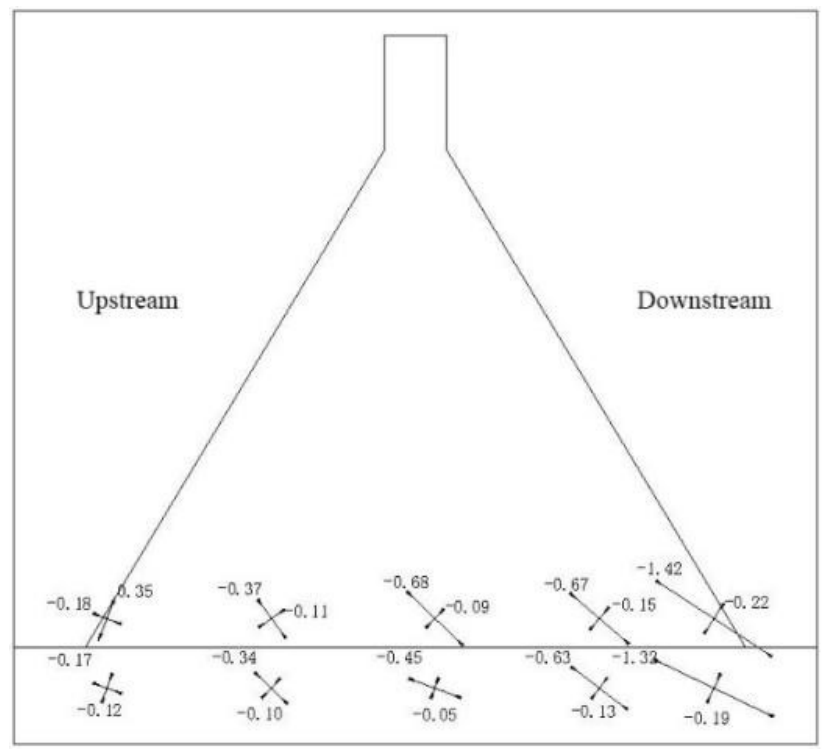

Figure 8: Vector diagram of main stress of test dam

pressive stress of the dam body gradually increases, especially in the toe of the dam. The compressive stress in the middle of the dam body changes little and is distributed evenly. The foundation of the dam is under pressure and is at its maximum downstream. Figure 10 shows the results of finite element calculation under the same condi-

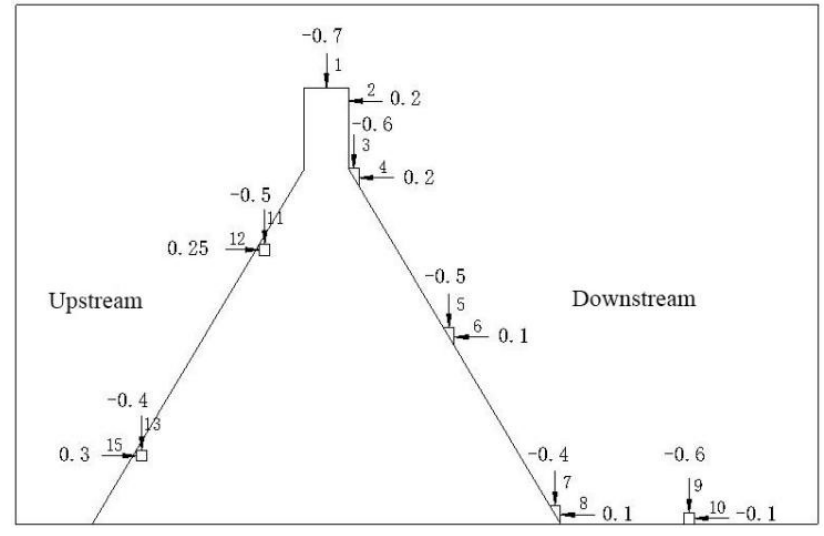

Figure 9: Test dam displacement diagram

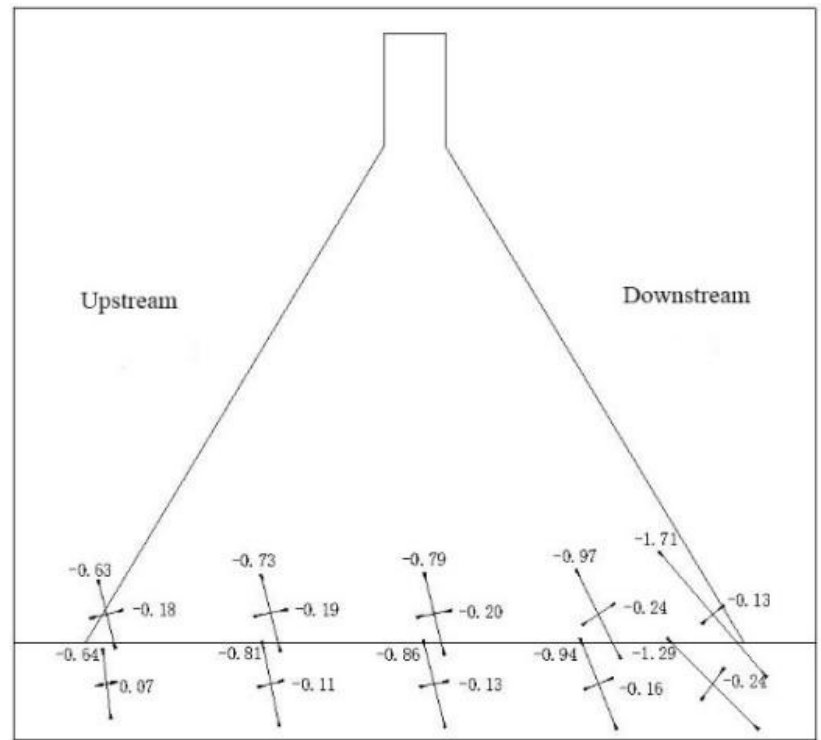

Figure 10: Vector diagram of main stress of dam by finite element calculation

tions. The dam body and foundation are also under compression, and only tensile stress appears at the lower dam foundation of dam heel. According to Figure 9, the vertical displacement of the dam body is all negative, and the horizontal displacement of the dam body is all positive, 


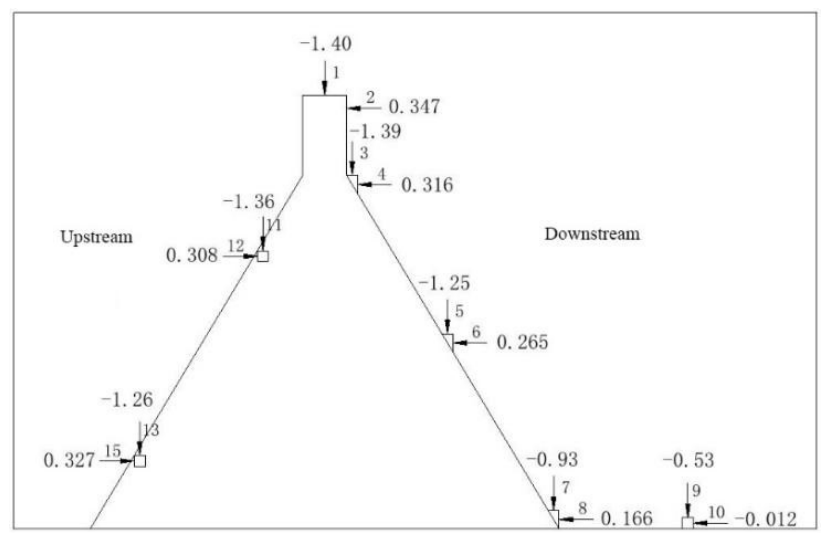

Figure 11: dam displacement diagram of finite element calculation

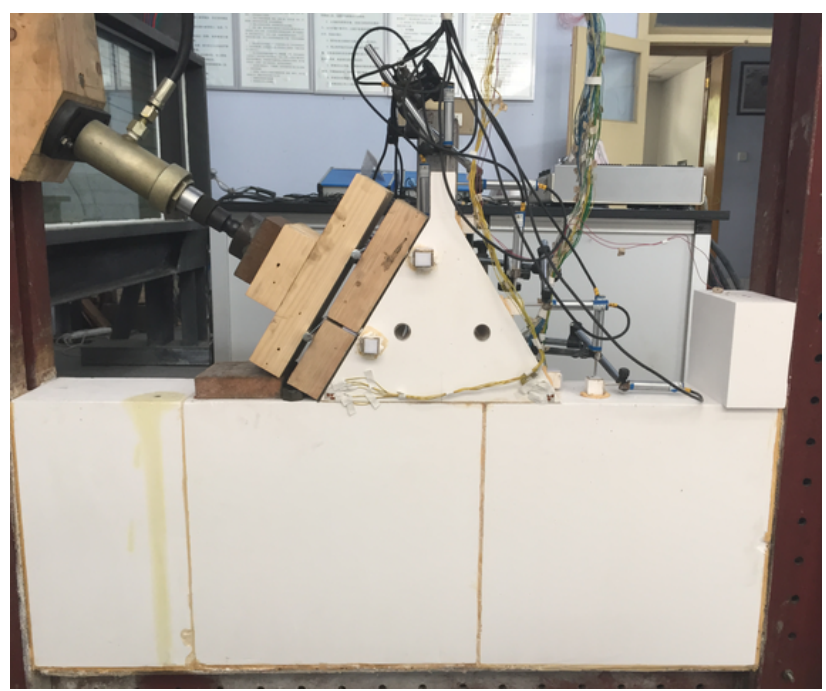

Figure 12: Layout of loading and measurement system

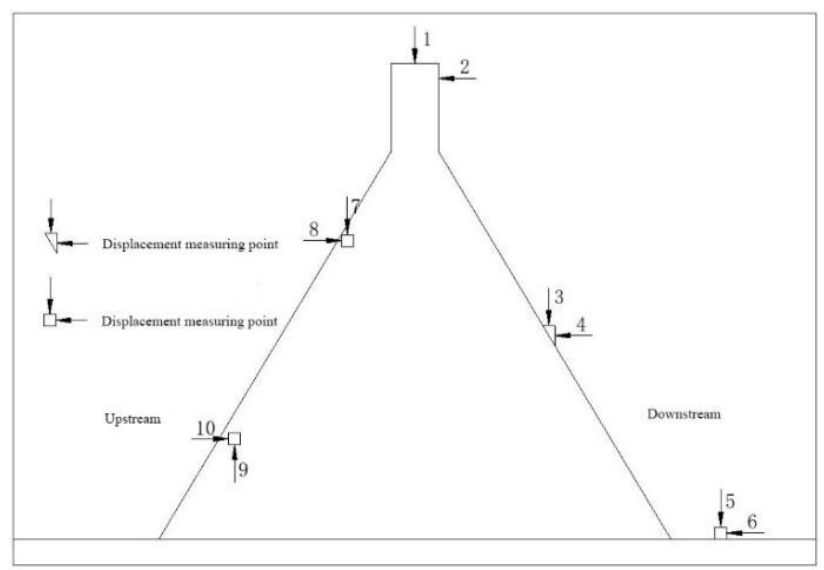

Figure 13: Arrangement of displacement measuring points

which shows a downstream displacement. The horizontal displacement of downstream surface increases with the increase of dam height, among which the horizontal dis-

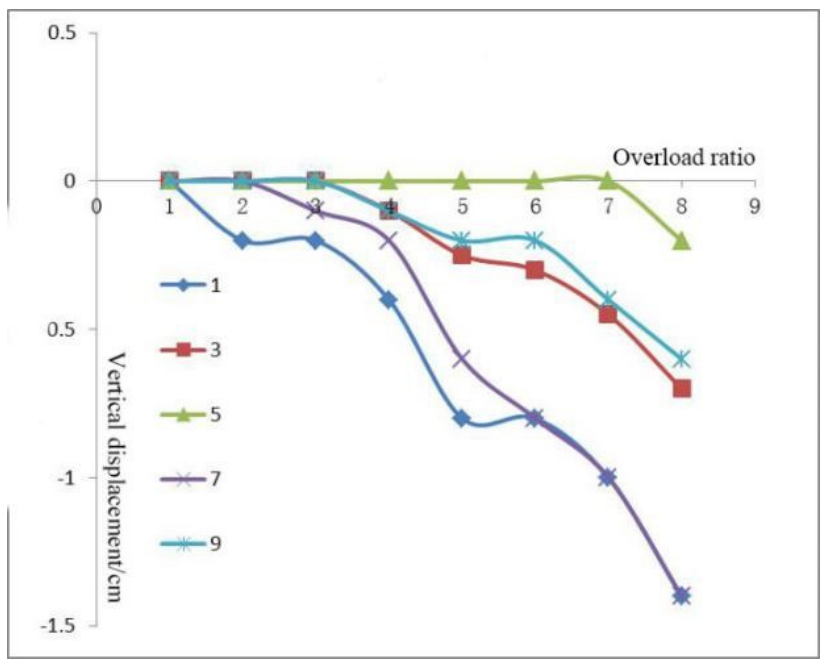

Figure 14: Variation curve of vertical displacement with overload multiple

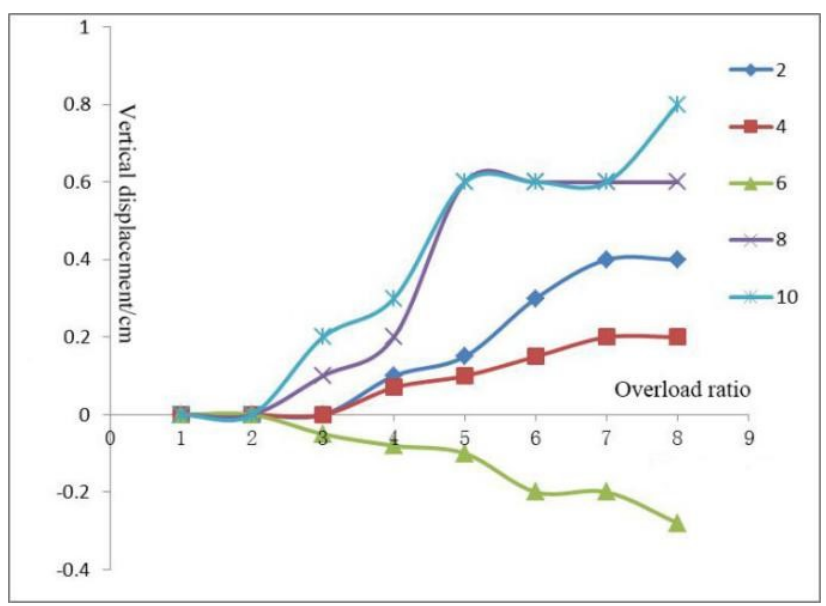

Figure 15: Variation curve of horizontal displacement with overload multiple

placement of 5 measuring point is negative, indicating that the dam foundation shifts upstream. According to the calculation in Figure 11, the horizontal displacement of measuring point 5 is also negative, and the law is consistent.

Table 4 compares the results of the test and the finite element stress calculation, and the main stress distribution law reflected by the test is basically reasonable. From the direction of the principal stress vector, the compressive stress values obtained by the test and calculation are in order of magnitude consistent. Table 5 compare the results of the test and the finite element displacement calculation, the displacement distribution law reflected by the test is reasonable. The experimental value is smaller than the finite element value, but it directly reflects the regularity of dam stress and deformation distribution. 

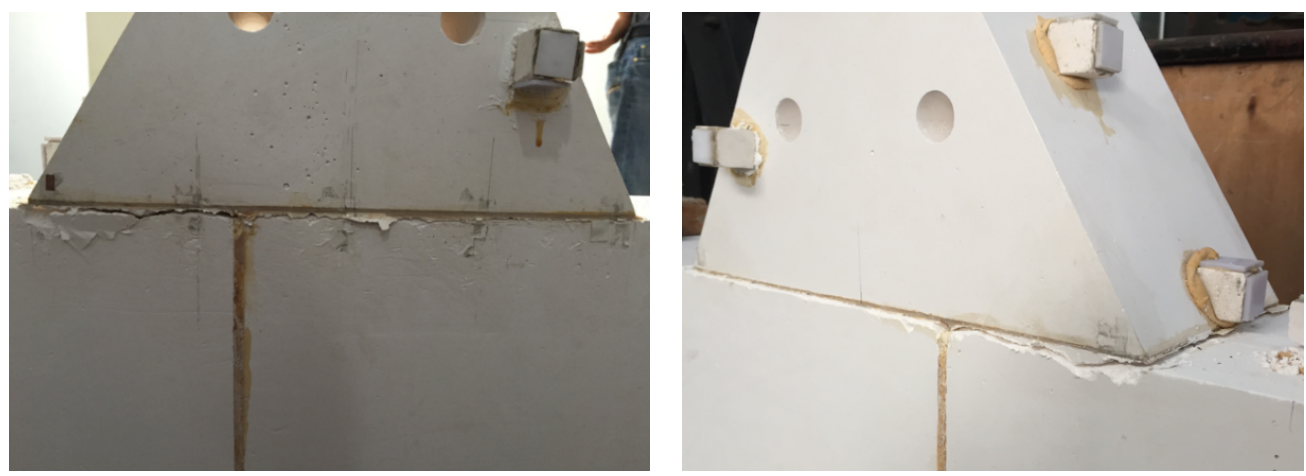

Figure 16: Failure pattern of dam (left and right sides of the model)
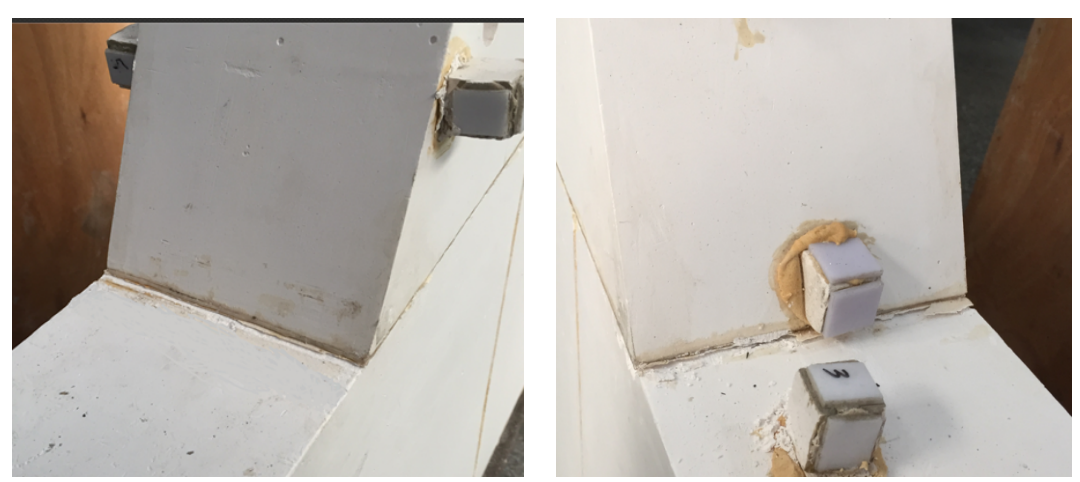

Figure 17: Local failure pattern of dam body (dam heel and foundation)
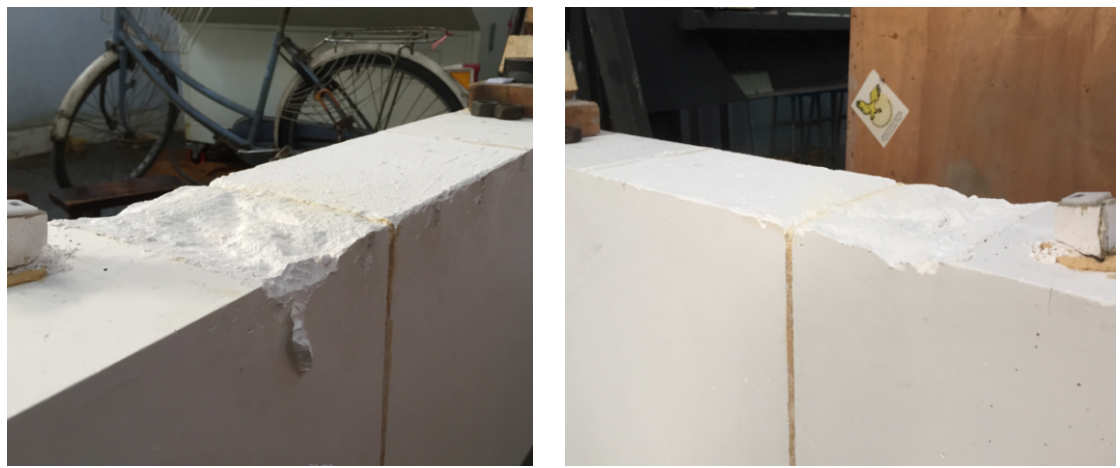

Figure 18: Failure pattern of foundation plane of dam body (toe of dam and foundation)
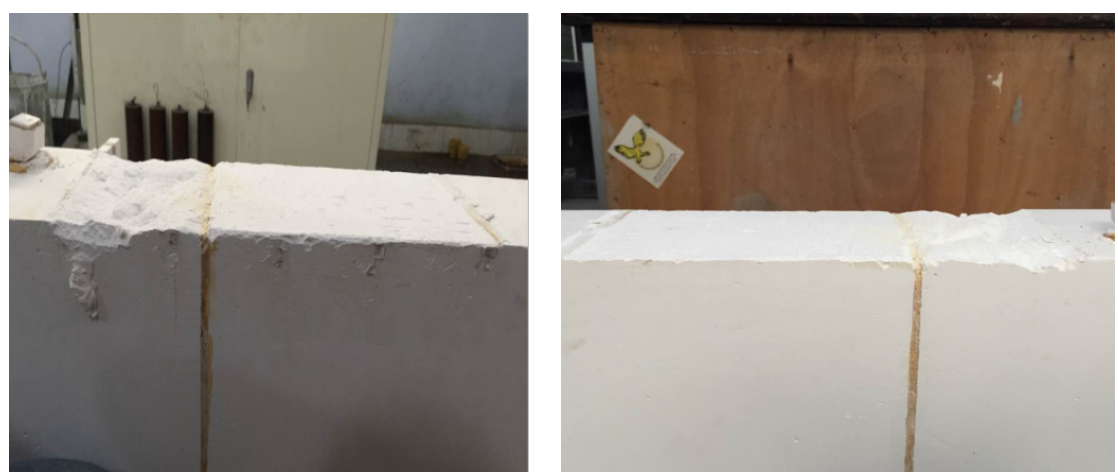

Figure 19: Failure pattern of foundation plane (left and right sides of the model) 


\subsection{Stress deformation results and analysis of dam body under overload condition}

In order to study the failure mechanism and destructive state of dam structure under overload condition, the test scheme is improved. The loading mode and measuring system layout of the improved test model are shown in. The curve of displacement measured by the dam with overload multiple is shown in Figure 14 and Figure 15.

In the horizontal displacement, the positive value represents the downstream displacement and in the vertical displacement, the positive value represents the vertical upward displacement. As can be seen from Figure 14, the vertical displacement value of each measurement point is negative, indicating that the dam body is shifting downward. When the overload multiple $\mathrm{Kp}=1.0 \sim 4.0$, the vertical displacement value of the dam body is small and changes little. When $4.0<\mathrm{Kp}<6.0$, the vertical deformation value of dam body increases. When Kp>6.0, the vertical deformation and displacement of the dam body increase again, and the deformation curve shows a linear growth trend. With the increase of overload times, the downward displacement value of dam body increases gradually.

It can be seen from Figure 15 that, except for the negative horizontal displacement at measuring point 6 , the measured values at the other points are all positive, indicating the downstream displacement of the dam. The horizontal displacement of point 2 is larger than that of point 4 , indicating that the downstream dam foundation tends to shift upstream. When the overload multiple $\mathrm{Kp}=1.0 \sim 3.0$, the horizontal displacement of the dam body is small, no change. When Kp>3.0, the horizontal displacement of the dam body shows an increasing trend. When Kp>7.0, the horizontal displacement of dam body does not change. It can be seen from the figure that the horizontal displacement of the upstream of the dam is larger than that of the downstream, and the maximum horizontal displacement of the dam occurs in the middle and lower part of the upstream. During the process of overload, the horizontal displacement of the dam body changes to the downstream. With the increase of overload times, the downstream displacement of the dam is more. When more than a certain number of increase, the dam body to the downstream change little.

\subsection{Discussion on failure pattern and failure mechanism}

Due to the structural model test using gypsum, there will be no obvious plastic deformation in the process of over- load, therefore in the change of displacement with the overload ratio no obvious turning point on the curve or large deformation stages, in order to get the overload failure mechanism of the dam body and sex, at the same time in order to prevent the dam suddenly brittle failure damages to the measuring instrument, after the dam overload to 8 times, will test measurement system, continue the overload test, finally the damage, the failure pattern of the model as shown in Figure $16 \sim 19$.

As shown in the figure above,Under the condition of overload, the failure areas of the model mainly show the toe of the dam and the foundation plane, and the most serious damage occurs at the toe of the dam. The upstream dam foundation is relatively complete, while the downstream dam foundation is seriously damaged, and partial compressive shear failure and spalling occur. From the left and right side of the model, the foundation building surface of the upstream section is relatively flat and smooth, while the foundation building surface of the downstream section is obviously uneven and irregular, and damage occurs at the shallow dam foundation of the downstream section.

\section{Conclusion}

The stress and displacement distribution characteristics of cemented sand and gravel dam body were studied by structural model test, and stress and displacement distribution of the dam body were obtained under the conditions of dead weight and normal water level. The results of test and finite element calculation show that the dam body and foundation are under the of dead weight and normal water level, and only a little tensile stress appears at the dam heel. The compressive stress of the dam body and the middle part of the dam foundation is evenly distributed. From the upstream to the downstream, the compressive stress of the dam body and foundation increases gradually, and reaches the maximum at the toe of the dam. The vertical displacement of dam body increases with the increase of dam height, and the horizontal displacement is shown as downstream displacement.

By using the method of water overload, the failure pattern and failure mechanism of the test model are obtained. Under the condition of overload, the horizontal displacement of the dam body is the downstream displacement, and the horizontal displacement of the downstream dam foundation is the upstream displacement. Generally speaking, the foundation surface destruction of the upstream section is relatively flat, the foundation surface de- 
struction of the downstream section is irregular, and compression shear failure occurs at the downstream dam foundation. With the increase of the overload factor, the pressure stress appears in the downstream dam foundation, and the shallow dam foundation and toe of the downstream dam begin to break. As the failure area increases, the mechanical properties of materials change, which is not enough to provide sufficient anti-slip force, and the failure occurs on the upstream surface.

Acknowledgement: We acknowledge the support received from National Key R \& D Program of China "highefficient development and utilization of water resource" (No. 2018YFC0406803).

\section{References}

[1] Amini Y., and Hamidi A., Triaxial shear behavior of cemented sand-gravel mixtures, Soil Behav. Geomech., 2014, 6(5), 76-83.

[2] Amini Y., Hamidi A., Asghari E., Amini Y., Hamidi A., and Asghari E., Shear strength characteristics of an artificially cemented sandgravel mixture, In: International Conference on Geotechnical \& Earthquake Engineering (9 October 2013).

[3] Sun M. Q., and Shi F. Y., The study of cemented sand and gravel constitutive model, In: Advanced Materials Research (May 2011), 2011, 243-249, 4596-4601.

[4] Hu H., and Zhang X. C., Failure mode analysis of cemented sand and gravel material dam, Sci. Adv. Mater., 2018, 10(9), 12861295.

[5] Send W., Fluid-structure interaction with ansys/fluent, in FluidStructure Interactions and Uncertainties, (11 February 2017), 2017, 35-57.

[6] Djodikusumo I., Diasta I. N., and Sanjaya Awaluddin I., Geometric modeling of a propeller turbine runner using ansys bladegen, meshing using ansys turbogrid and fluid dynamic simulation using ansys fluent, Appl. Mech. Mater., 2016, 842, 164-177.

[7] Erdogan M., and Guven I., "Use of commands in ANSYS." Finite Elem. Method and Appl. Eng. Using ANSYS, 2015, 281-312.

[8] Christof G., Konfiguration von ANSYS Workbench, Praxisbuch FEM Mit ANSYS Workbench, 2014, 395-398.

[9] Nakasone Y., Yoshimoto S., and Stolarski T. A., Application of ANSYS to contact between machine elements, Eng. Anal. ANSYS Software, 2006, 331-451.
[10] Kathryn T. M., and Thompson J. M., Introduction to ANSYS and finite element modeling, ANSYS Mech. APDL for Finite Elem. Anal., 2017, 1-9.

[11] Christof G., Praxisbuch FEM Mit ANSYS workbench, in Praxisbuch FEM Mit ANSYS Workbench, (8 October 2018), 2018.

[12] Stolarski T., Nakasone Y., and Yoshimoto S., Application of ANSYS to stress analysis, Eng. Anal. ANSYS Software, 2018, 51-163.

[13] Nakasone Y., Yoshimoto S., Engineering analysis with ANSYS software, Elsevier Butterworth-Heinemann, 2006.

[14] Chochola J. Boeing model 727 structural test program, Transport Aircr. Des. Oper.Meeting, 1964.

[15] Bacci S., and Bartolucci F., A Multidimensional finite mixture structural equation model for nonignorable missing responses to test items, struct, Equation Model.: A Multidiscip. Journal, 2015, 22(3), 352-365.

[16] Feldt R. C., Test of a social cognitive structural model of academic satisfaction, PsycEXTRA Dataset, 2011.

[17] Wolpoff M. E., Structural equation model test of factors of sport commitment, PsycEXTRA Dataset, 2006.

[18] Devasena M. S. G., and Valarmathi M. L., Multi agent based framework for structural and model based test case generation, Procedia Eng., 2012, 38, 3840-3845.

[19] Papadimitriou C., Beck J. L., Katafygiotis L. S., Updating robust reliability using structural test data, Probab. Eng. Mech., 2001, 16(2), 103-113.

[20] Xie Q., and Andrews S., Do test design and uses influence test preparation? Testing a model of washback with structural equation modeling, Lang. Test., 2013, 30(1), 49-70.

[21] Gotlieb A., Botella B., Rueher M., A CLP framework for computing structural test data, Lect. Notes Comput. Sci., 2000, 1861.

[22] Xie Q., and Andrews S., Do test design and uses influence test preparation? Testing a model of washback with structural equation modeling, Lang. Test., 2013, 30(1), 49-70.

[23] Schwirian R. E., Pressure pulse test results and qualification of the flash-34 flexible structural member model with a surge tank attached to the test vessel (lwbr development program), Nasa Sti/recon Tech. Rep.N, 1977, 78.

[24] Akhmet M., Fen M. O., Homoclinic and heteroclinic motions in economic models with exogenous shocks, Appl. Math. Nonlinear Sci., 2016, 1(1), 1-10.

[25] Zhu L. L., Pan Y., and Wang J. T., Affine transformation based ontology sparse vector learning algorithm, Appl. Math. Nonlinear Sci., 2017, 2(1), 111-122.

[26] Shvets A., and Makaseyev A., Deterministic chaos in pendulum systems with delay, App. Math. Nonlinear Sci., 2019, 4(1), 1-8. 